\title{
Morphological evidence for the existence of nitric oxide and carbon monoxide pathways in the rat islets of Langerhans: An immunocytochemical and confocal microscopical study
}

\author{
P. Alm ${ }^{1}$, P. Ekström ${ }^{2}$, R.Henningsson ${ }^{3}$, I. Lundquist ${ }^{3}$ \\ ${ }^{1}$ Department of Pathology, University of Lund, Sweden \\ ${ }^{2}$ Department of Zoology, University of Lund, Sweden \\ ${ }^{3}$ Department of Pharmacology, University of Lund, Sweden
}

\begin{abstract}
Aims/hypothesis. To map the cellular location of inducible and constitutive nitric oxide synthase and haem oxygenase in rat islets to clarify the morphological background to putative nitric oxide and carbon monoxide pathways.

Methods. Immunocytochemistry and confocal microscopy.

Results. After treatment with endotoxin, immunoreactivity for inducible nitric oxide synthase was expressed in a large number of islet cells, most of which were insulin-immunoreactive beta cells and in single glucagon-immunoreactive and pancreatic polypeptide-immunoreactive cells. Somatostatin-immunoreactive cells lacked immunoreactivity for inducible nitric oxide synthase. In untreated rats, immunoreactivity for constitutive nitric oxide synthase occurred in the majority of insulin-immunoreactive and glucagon-immunoreactive cells, in most pancreatic polypeptide-immunoreactive and somatostatin-immunoreactive cells and in islet nerves. Similarly, immunoreactivity for constitutive haem oxygenase was detected in all four types of islet cells. Endotoxin
\end{abstract}

treatment did not change the pattern of immunoreactivity for constitutive and inducible haem oxygenase. After treatment with alloxan, insulin-immunoreactivity was observed only in single islet cells, being almost devoid of immunoreactivity for constitutive nitric oxide synthase and haem oxygenase.

Conclusion/interpretation. In vivo endotoxin-induced expression of inducible nitric oxide synthase in insulin-producing and in scattered glucagon-producing and pancreatic polypeptide-producing cells strengthens previous suggestions of a pathophysiological role for inducible nitric oxide synthase in the development of insulin-dependent diabetes mellitus. The presence of constitutive nitric oxide synthase and haem oxygenase in all four types of islet cells, together with recent functional data of ours support roles for nitric oxide and carbon monoxide as intracellular, paracrine or neurocrine modulators of islet hormone secretion. [Diabetologia (1999) 42: 978-986]

Keywords Pancreatic islets, nitric oxide synthase, haem oxygenase, imunocytochemistry, confocal microscopy.
Received: 19 November 1998 and in revised form: 22 March 1999

Corresponding author: P. Alm, MD, PhD, Department of Pathology, University Hospital, S-22185 Lund, Sweden

Abbreviations: CO, Carbon monoxide; $\mathrm{HO}$, haem oxygenase; $\mathrm{HO}-1$, inducible haem oxygenase; HO-2, constitutive haem oxygenase; NO, nitric oxide; NOS, nitric oxide synthase; GLUC, glucagon; IG, immunoglobulins; INS, insulin; IR, immunoreactive; LPS, lipopolysaccharide (endotoxin); iNOS, inducible nitric oxide synthase; cNOS, constitutive nitric oxide synthase; eNOS, endothelial nitric oxide synthase; nNOS, neuronal nitric oxide synthase; PP, pancreatic polypeptide; SOM, somatostatin; ZnPP, zinc protoporphyrin; FITC, fluorescein isothiocyanate conjugated. 
Nitric oxide (NO) is a free radical gas that conveys biological information in a way greatly differing from that of the classical transmitters. In the nervous system NO does not act on conventional receptors but through effects on various regulatory processes, intracellularly or in the membrane [1]. The formation of NO is catalysed by the enzyme nitric oxide synthase (NOS), in a reaction in which L-arginine and oxygen are converted to $\mathrm{NO}$ and citrulline. There are two major types of NOS enzymes; one inducible isoform $i$ NOS, originally described in macrophages and also shown to be expressed in a variety of mammalian tissues among which are the islets of Langerhans $[2,3]$, and constitutive isoforms ( $c$ NOS) present in neurons ( $n$ NOS) and endothelial cells (eNOS) [1]. We and others [4-8] have shown previously that the pancreatic islets contain a constitutive NOS as determined by histochemical, immunocytochemical and biochemical methods. Islet $i$ NOS has been implicated as an important factor in the pathogenesis of Type I (insulin-dependent) diabetes mellitus [2,3], whereas islet $c$ NOS has been suggested to be involved in the physiological regulation of insulin and glucagon secretion [4-15]. Thus, both $c$ NOS and $i$ NOS seem to be of great physiological and pathophysiological importance in the pancreatic islets. Constitutive nitric oxide synthase was localised by the use of an antiserum to the neuronal isoform of $c$ NOS.

There are diverging results as to the cellular location of the NOS isoforms within the islets, i.e. whether only the insulin producing beta cells or, in addition, other endocrine cell types such as glucagon-producing, somatostatin-producing, and pancreatic polypeptide (PP)-producing cells also contain NOS activity [4-8, 16-18]. Further, in this context, attention has also been drawn to another gaseous molecule, carbon monoxide $(\mathrm{CO})$, since a number of recent studies have shown that $\mathrm{CO}$ may serve as a neuronal messenger molecule similar to NO [19-21]. Carbon monoxide is produced by the action of haem oxygenase (HO), at which haem from haemoglobin is degraded to $\mathrm{CO}$ and biliverdin [19-22]. The latter compound can then be converted to bilirubin, which is an important antioxidant, the reaction being catalysed by the enzyme biliverdin reductase. Similar to NOS, HO consists of at least two isoenzymes, an inducible (HO-1), and a constitutively expressed isoform (HO-2) [19-21]. Expression of HO-1 is induced by various stress factors, e.g. fever, starvation, oxidative injury. A cytokine-induced expression of a protein (presumably HO-1) has previously been observed in islet tissue, and suggested to be a protective mechanism against oxidative stress [2, 3, 23-25]. Constitutive haem oxygenase is highly expressed in nervous tissue, in which $\mathrm{CO}$ may have a transmitter-like function $[19,20]$ and recent findings of ours suggest a role for $\mathrm{CO}$ in the regulation of the release of islet hormones in rats [26].
To further clarify the morphological background to the putative $\mathrm{NO}$ and $\mathrm{CO}$ functional pathways in the islets of Langerhans, the aim of this study was to map the cellular location of $i \mathrm{NOS}, c \mathrm{NOS}, \mathrm{HO}-1$ and HO-2 in islets of normal and alloxan diabetic rats by means of combined immunocytochemical and confocal microscopical methods.

\section{Materials and methods}

Tissue handling. Female Sprague-Dawley rats (300-400 g body weight, aged about 3-4 months) were purchased from B\&K Universal, Stockholm, Sweden. The animals had free access to water and standard pellets and were used in different experimental groups consisting of four to six animals. One group consisted of rats that received no treatment. One group of rats was given LPS (lipopolysaccharide endotoxin from salmonella typhimurium, Sigma, St Louis, Mo., USA; $10 \mathrm{mg} / \mathrm{kg}$ i.p., dissolved in saline) and used after $6 \mathrm{~h}$, at which time there is a high expression of $i$ NOS [34]. One group was treated with alloxan (Sigma; $60 \mathrm{mg} / \mathrm{kg}$ i.v., dissolved in saline with the addition of a drop of $0.1 \mathrm{~N}$ acetic acid to acidify the solution) and killed after 5 days. Plasma glucose was determined by a glucose oxidase method $[18,27]$ to ensure that the animals had become diabetic. The concentrations of plasma glucose in freely fed diabetic animals were $15.1-38.7 \mathrm{mmol} / \mathrm{l}$ (total range) compared with $8.9-11.7 \mathrm{mmol} / \mathrm{l}$ in normal rats. The rats were anaesthesized with ketamine $(100 \mathrm{mg} / \mathrm{kg}$ intramuscular; Ketalar, Parke Davis, Barcelona, Spain) and xylazin $(15 \mathrm{mg} / \mathrm{kg}$ intramuscular; Rompun, Bayer, Leverkusen, Germany) and perfused transcardially through the ascending aorta, first with $100 \mathrm{ml}$ of ice-cold calcium-free Krebs buffer (containing $0.5 \mathrm{~g} / 1$ sodium nitrite and $10.000 \mathrm{iU} / \mathrm{l}$ of heparin), and then with $300 \mathrm{ml}$ of an ice-cold, freshly prepared solution of $4 \%$ formaldehyde in phosphate buffered saline (PBS, $0.1 \mathrm{~mol} / \mathrm{l}$, pH 7.4). The pancreatic glands were then rapidly dissected out and divided into pieces, which were fixed in the same fixative for 4 hours. After this they were rinsed in ice-cold $15 \%$ sucrose in PBS (three rinses during $48 \mathrm{~h}$ ). The tissue specimens were frozen in isopentane at $-40^{\circ} \mathrm{C}$ and then stored at $-70^{\circ} \mathrm{C}$. Principles of laboratory animal care (NIH publication No 85-23 1985) were followed and the experimental design was also approved by the animal ethics committee of the University of Lund, Lund, Sweden.

Immunocytochemistry. Cryostat section were cut at a thickness of $8 \mu \mathrm{m}$ and thaw-mounted onto chrom alum-coated glass slides and air dried for $30 \mathrm{~min}$ to $1 \mathrm{~h}$. To show $i$ NOS, $n$ NOS, HO-1 and HO-2, sections were pre-incubated in PBS with $0.2 \%$ Triton X-100 for about $2 \mathrm{~h}$, and then incubated for 2 days in the presence of rabbit antisera to $i$ NOS, $n$ NOS, HO1 or HO-2. The antiserum to $i$ NOS (1:500) was generated in rabbits against a 25 amino acid peptide of a cloned inducible NOS from a murine macrophage cell line [28, 29]. The antisera to $n$ NOS were generated in rabbits against a 15 amino acid sequence ( $n$ NOS-15, 1:1280) [30], or a 21 amino acid sequence ( $n$ NOS-21, peptide $58 ; 1: 2000$ ) [31] from the C-terminal part of a cloned rat cerebellar NOS [32]. The antiserum to HO-1 (1:500; code OSA 100, StressGen Biotechnol, Victoria, Canada) was generated in rabbits against rat liver HO-1. The rabbit HO-2 antiserum (1:1000, code OSA-200; StressGen) was generated in rabbits against rat testes $\mathrm{HO}-2$. After rinsing in PBS (three rinses during $10 \mathrm{~min}$ ), the sections were incubated for $90 \mathrm{~min}$ with fluorescein isothiocyanate conjugated (FITC) 
swine anti-rabbit immunoglobulins (IG) (1:80; Dakopatts, Stockholm, Sweden) or Texas red-conjugated affinity purified $\mathrm{F}\left(\mathrm{ab}^{\prime}\right)_{2}$ fragments of donkey anti-rabbit IG (1:80; code 711-076-132; Jackson Immuno Research, West Grove, Pa., USA). After rinsing, the sections were mounted in PBS/glycerol with p-phenylenediamine to prevent fluorescence fading [33].

To show two antigens simultaneously [34], sections were incubated overnight with $i$ NOS, $n$ NOS, or HO- 2 antisera (see above), rinsed and then incubated overnight with antisera generated in guinea-pigs to insulin (1:16000), glucagon (1:4000) and pancreatic polypeptide (1:500) (the latter antisera purchased from Linco Res, St Louis, Mo., USA), and a mouse monoclonal antiserum to somatostatin (1:5 of a prediluted antiserum; cat no 8330-0496, Biogenesis, Poole, England). After rinsing, the sections were incubated for $90 \mathrm{~min}$ with FITC goat anti-guinea-pig IG or goat anti-mouse IG (1:80; Sigma, St Louis, Mo., USA), rinsed and then incubated with Texas red conjugated affinity purified $\mathrm{F}\left(\mathrm{ab}^{\prime}\right)_{2}$ fragments of donkey anti-rabbit IG (1:80; see above). The sections were rinsed and mounted as described above. An Olympus $3 \times 50$ fluorescence microscope (LRI Instrument AB, Lund, Sweden) equipped with epi-illumination and appropriate filter settings for Texas Red-immunofluorescence and FITC-immunofluorescence was used for the examinations of the sections [35].

The primary and secondary antisera were diluted in PBS. In control experiments no immunoreactivity could be detected in sections incubated in the absence of the primary antisera or with $n$ NOS-15, HO-2, glucagon, somatostatin or pancreatic polypeptide antisera absorbed with excess of the corresponding immunizing antigen $(100 \mu \mathrm{g} / \mathrm{ml})$. No absorption controls could be done with the $i$ NOS or $n$ NOS-21 antisera as antigenic substances were not available. The characteristics of the $i$ NOS and the $n$ NOS antisera have been presented previously [29-31]. In control experiments $i$ NOS-immunoreactivity was only observed in LPS-induced tissues (macrophages in lung and liver), in which no $n$ NOS-immunoreactivity could be seen. As cross reactions to antigens sharing similar amino acid sequences cannot be completely excluded the structures shown are referred to as $i$ NOS-, $n$ NOS-, HO-1-, HO-2-, insulin-(INS-), glucagon-(GLUC-), pancreatic polypeptide-(PP-), or somatostatin-(SOM-) immunoreactive (IR).

Confocal microscopy. To evaluate whether two immunoreactivities were colocalized within the same cellular structures, sections were analysed in a confocal laser scanning microscope (Multiprobe 2001 TM CLSM; Molecular Dynamics) equipped with an Ar/Kr laser and an inverted Nikon Diaphot TMD microscope as described elsewhere [35].

\section{Results}

No $i$ NOS-immunoreactivity could be detected in islets of untreated animals. After LPS treatment, $i$ NOS-immunoreactivity was expressed in a large number of islet cells, which were diffusely spread over the islets (Fig. 1A, D, G, J). Double immunostaining showed that these cells were also INS-IR, which was further verified by confocal microscopy (Fig. 1C).

Moreover, single $i$ NOS-IR cells also displayed GLUC-immunoreactivity and PP-immunoreactivity (Fig. 1F, I) but in most of the GLUC-IR and PP-IR cells $i$ NOS-immunoreactivity was lacking. No $i$ NOSIR cells expressed SOM-immunoreactivity (Fig. 1L). In comparison, treatment with LPS did not seem to change the $n$ NOS-immunolabelling pattern with both the $n$ NOS antisera used.

Constitutive NOS expressed as $n$ NOS-immunoreactivity could be detected in the cytoplasm of most islet cells of untreated animals (Fig.2A, D, G). The number and distribution patterns of $n$ NOS-IR cells were similar with the two NOS antisera used, although the intensity of the NOS-immunofluorescence was weaker with the $n \mathrm{NOS}-21$ than with the $n$ NOS-15 antiserum. Vessels of capillary size, between the trabecula of islet cells (Fig. 2G) and between exocrine acini, were accompanied by varicose NOS-IR nerve terminals, which were also found around arteries of various sizes. No $n$ NOS-immunoreactivity could be detected in endothelial cells of the islet microvasculature.

Double immunolabelling showed that $n$ NOS-immunoreactivity was in most INS-IR cells (Fig. 2A-C). In the periphery of the islets there were, however, several $n$ NOS-IR cells which lacked INS-immunoreactivity. Most GLUC-IR cells, which were located along the periphery of the islets, were also $n$ NOS-IR (Fig. 2D-F), although single GLUC-IR cells were discovered which lacked $n$ NOS-immunoreactivity. Pancreatic polypeptide-IR and some SOM-IR cells, which were also located in the periphery of the islets, also expressed $n$ NOS-immunoreactivity (data not shown), which in the SOM-IR cells were as far as to the ends of their long and gracile dendritic processes.

In the cytoplasm of almost all islet cells HO-2 immunoreactivity could be detected (Fig. 3 A, D, G, $\mathrm{L})$. Double immunolabelling in combination with confocal microscopy revealed that most INS-IR cells also showed HO-2 immunoreactivity, although there were HO-2 IR cell in the periphery of the islets that lacked INS-immunoreactivity (Fig.3A-C). Further, along the periphery of the islets there was a broad ring of GLUC-IR, which also were HO-2 IR (Fig. 3 D-F) and dispersed PP-cells and SOM-IR cells with extended processes. These also expressed HO-2 immunoreactivity (Fig. 3G-K, L-N). No HO-1 immunoreactivity could be detected in any type of islet cells.

After treatment with alloxan almost no specific $n$ NOS-immunoreactivity and HO-2 immunoreactivity was discovered in most of the damaged beta cells and INS-immunoreactivity was only seen in single islet cells, which were vacuolized and enlarged. In comparison, $n$ NOS-immunoreactivity and $\mathrm{HO}-2$ immunoreactivity was well preserved only in non beta cells (GLUC-IR cells and others) (data not shown). 

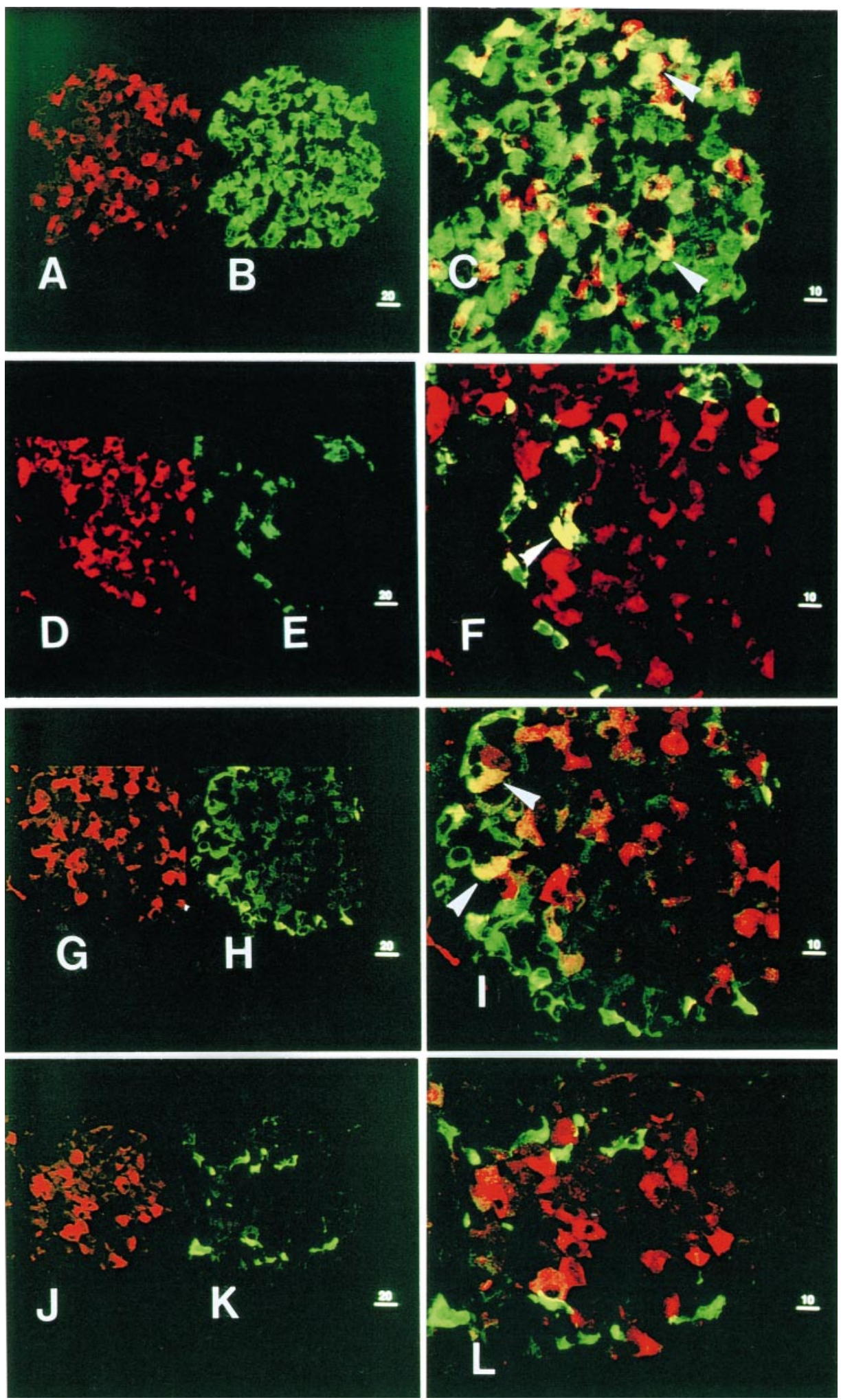

Fig. 1A-L. Confocal microscopy of rat islets of Langerhans after treatment with LPS. Left panel: red fluorescence in $\mathbf{A , D , G}$ and $\mathbf{J}$ indicating expression of $i$ NOS-immunoreactivity (Texas red immunofluorescence). Middle panel: green fluorescence (FITC-immunofluorescence) shows immunoreactivities for insulin (B), glucagon (E), pancreatic polypeptide $(\mathbf{H})$ and soma-

tostatin (K). Right panel: overlay picture of $\mathbf{A}+\mathbf{B}(=\mathbf{C})$, $\mathbf{D}+\mathbf{E}(=\mathbf{F}), \mathbf{G}+\mathbf{H}(=\mathbf{I})$ and $\mathbf{J}+\mathbf{K}(=\mathbf{L})$. Cells showing yellowish fluorescence (arrowheads) indicate colocalization of $i$ NOS/insulin (C), $i$ NOS/glucagon $(\mathbf{F})$, and $i$ NOS/pancreatic polypeptide (I). Bars with numerals indicate lengths $(\mu \mathrm{m})$ 

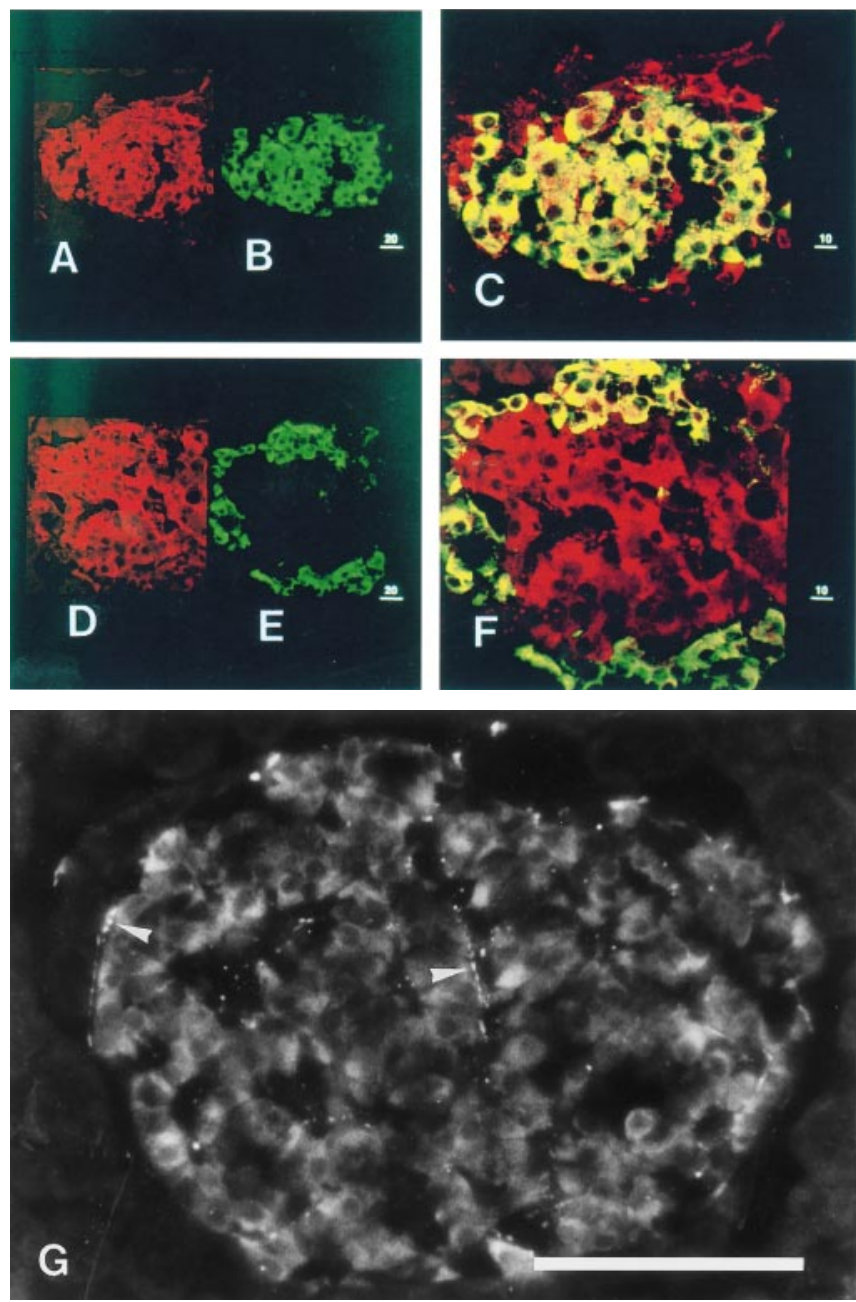

Fig. 2 A-G. Confocal microscopy of islets of Langerhans of untreated rats. Left panel: red fluorescence in $\mathbf{A}$ and $\mathbf{D}$ (Texas Red immunoflurescence) indicates $n$ NOS-immunoreactivity. Middle panel: green fluorescence (FITC-immunofluorescence) shows immunoreactivities for insulin $(\mathbf{B})$ and glucagon (E). Right panel: overlay picture of $\mathbf{A}+\mathbf{B}(=\mathbf{C})$, and $\mathbf{D}+\mathbf{E}$ $(=\mathbf{F})$. Yellowish fluorescent cells indicate colocalization of $n \mathrm{NOS} /$ insulin $(\mathbf{C})$ and $n \mathrm{NOS} /$ glucagon $(\mathbf{F})$. Bars with numerals indicate lengths $(\mathrm{mm})$. G. Rat islet of Langerhans with $n$ NOSIR varicose nerve terminals (arrowheads) running along vessels of capillary size between endocrine cells. FITC-immunofluorescence. Bar $=100 \mu \mathrm{m}$

\section{Discussion}

A characteristic of Type I diabetes is a local inflammatory reaction in the pancreatic islets that are undergoing autoimmune destruction $[2,3]$. Nitric oxide has been proposed as a possible mediator in the damage process to the insulin producing beta cells and there is ample in vitro evidence that IL-1 and other cytokines are able to induce $i$ NOS expression in islet tissue $[2,3]$. The pancreatic islet consists, however, of a heterogeneous cell population, making it difficult to localize the cellular source of $i$ NOS expression and NO production. It was recently shown that rat islets exposed to cytokine in vitro expressed $i$ NOS in their insulin cells whereas the glucagon cells seemed unaffected [7]. No data on the possible existence of $i$ NOS in somatostatin cells or PP-cells have so far appeared in the literature.

Lipopolysaccharide (endotoxin) is known to stimulate cytokine production $[2,3]$. It is important, however, to note that apart from cytokines, other factors also have been suggested to serve as direct or indirect mediators of effects of LPS. Thus, it is known that LPS may cause the synthesis of reactive oxygen species such as superoxide and hydrogen peroxide, and that NO can combine with superoxide to form the potent oxidizing agent peroxynitrite $[2,3]$. Hence, our immunocytochemical data cannot be extrapolated to answer questions on the intimate mechanisms of immune destruction of the islet beta cells. Our results show that after treatment with LPS in vivo $i$ NOS is expressed in most INS-IR cells and also, although to a much lesser extent, in scattered GLUC-IR and PPIR cells. No $i$ NOS was detected in cells immunostained for somatostatin. Our in vivo data of $i$ NOS expression in INS-IR cells, agree with findings of previous studies of islets exposed to cytokine in vitro $[2,3,7]$. The observation that $i$ NOS expression can be elicited in GLUC-IR cells and PP-IR cells has not been described previously. This may be explained by differences between the in vitro and the in vivo situation and the possible induction by LPS of unknown $i$ NOS stimulatory factors. On the other hand, since the fraction of $i$ NOS positive cells among the GLUC-IR cell and PP-IR cells is much smaller than among the INS-IR cells, it is not inconceivable that refined techniques such as confocal microscopy are required to observe these $i$ NOS positive GLUC-IR cell and PP-IR cells. It is difficult to explain why SOM-IR cells are not influenced by LPS. It has been shown $[36,37]$ that cells producing somatostatin in contrast to those producing insulin, glucagon and PP are not members of the group of endocrine cells belonging to the amine precursor uptake and decarboxylation series. Whether the ability of endocrine cells to store amine is coupled to that of expressing $i$ NOS remains to be explained. If NO finally turns out, however, to be of pathophysiological importance in the development of Type I diabetes, it is notable that not only insulin cells but also GLUC-IR cells and PP-IR cells are able to express $i$ NOS. Whether the number of these non-beta cells observed expressing $i$ NOS is, however, enough to actually contribute to damaging the beta cells remains to be explained. It is also tempting to speculate that NO derived by the action of $i$ NOS in the glucagon cells is at least partly responsible for the increased glucagon secretion in the diabetic condition. Indirectly, such a mechanism might also explain why there is an increased somatostatin response to glucagon in diabetes. 

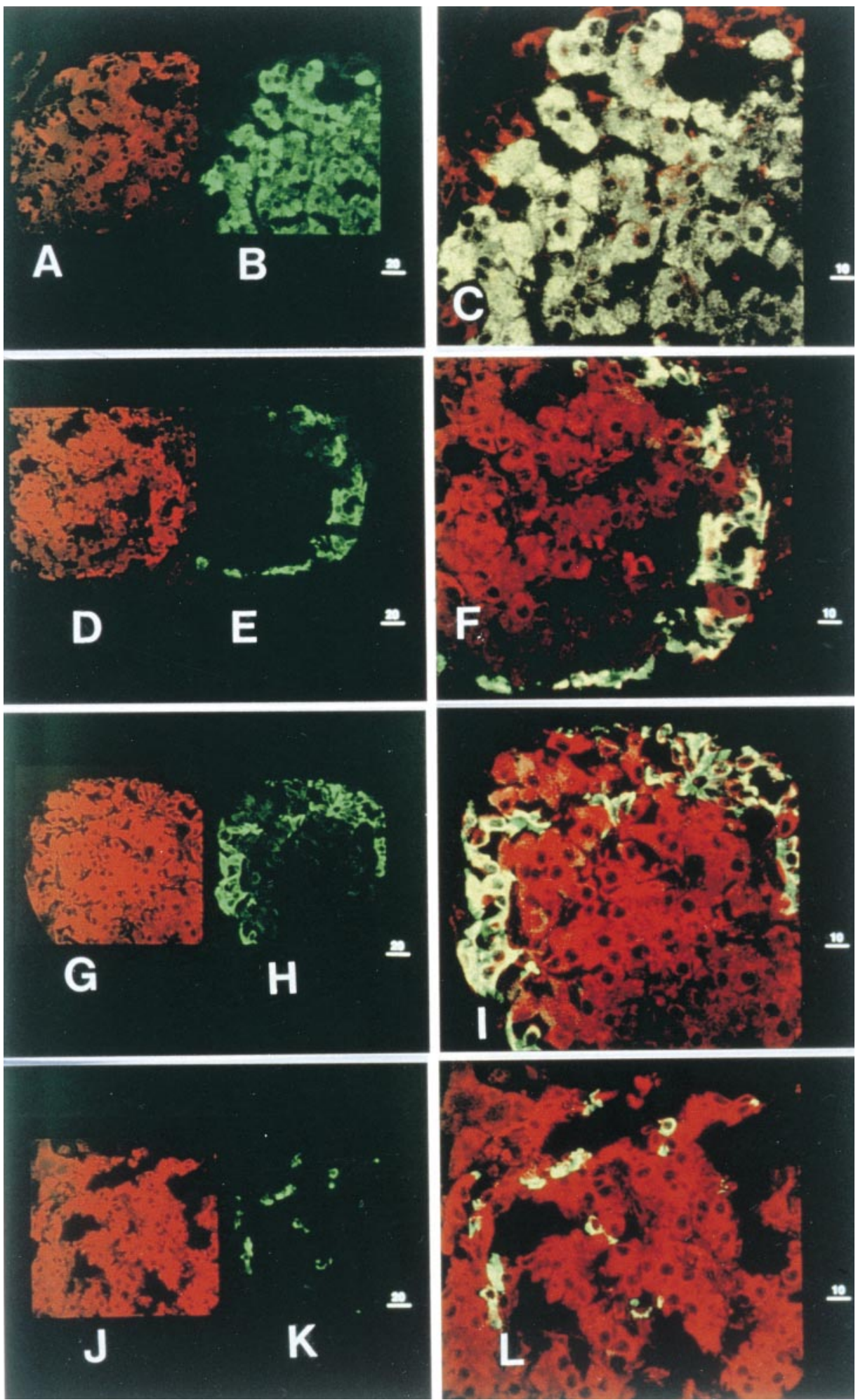

Fig. 3 A-L. Confocal microscopy of islets of Langerhans of untreated rats. Left panel: red fluorescence in $\mathbf{A}, \mathbf{D}, \mathbf{G}$ and $\mathbf{J}$ displays expression of HO-2 immunoreactivity (Texas red immunofluorescence). Middle panel: green fluorescence (FITC-immunofluorescence) shows immunoreactivities for insulin (B), glucagon $(\mathbf{E})$, pancreatic polypeptide $(\mathbf{H})$ and somatostatin

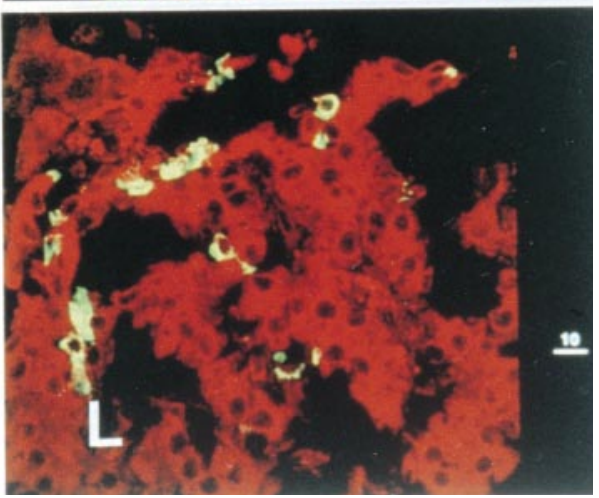

(K). Right panel: overlay picture of $\mathbf{A}+\mathbf{B}(=\mathbf{C}), \mathbf{D}+\mathbf{E}$ $(=\mathbf{F}), \mathbf{G}+\mathbf{H}(=\mathbf{I})$ and $\mathbf{J}+\mathbf{K}(=\mathbf{L})$. Cells showing yellowish fluorescence indicate colocalization of HO-2/insulin (C), HO2/glucagon (F), HO-2/pancreatic polypeptide (I), and HO-2/ somatostatin $(\mathbf{L})$. Bars with numerals indicate lengths $(\mu \mathrm{m})$ 
Our data show that all four endocrine cell types, i.e. those containing insulin, glucagon, somatostatin and PP showed immunoreactivity for two different antisera of the neuronal isoform of constitutive NOS. As previously discussed it has been known for several years $[2,3]$ that rat pancreatic islets are able to express the inducible NOS isoform after treatment in vitro with different cytokines. The possibility of a constitutive NOS isoform being present has, however, been a matter of debate. We and others $[4,5,7,8$, 16,38 ] have previously observed $c$ NOS activity in rat and mouse islet cells by both histochemical (NAD$\mathrm{PH}$-diaphorase activity) and immunocytochemical methods. In a recent study, $n$ NOS immunoreactivity was shown in rat islets with a weak intensity [38] that was apparently lower than the findings in this study. This is possibly due to differences in methodology and $n$ NOS antisera used but also to differences in brightness of the fluorophores of the secondary antibodies [39]. In comparison, other studies carried out with other NOS antisera as well as with the NAD$\mathrm{PH}$-diaphorase method were either unable to show $c$ NOS activity in rat islet cells or reported that only cells containing somatostatin or islet nerves or both were positive for NOS [40, 41, 42]. The reasons for these discrepancies are not known. The existence of different local isoforms, differences between antisera in recognizing epitopes or differences in methodology are possible explanations. Further, the recent observation that a constitutive $e$ NOS is localized to glucagon and somatostatin (but not to insulin cells) in rat islets suggests the possibility that both $e$ NOS and $n$ NOS are localized in the same cell type $[5,18]$. In the present study using two antisera of different sources directed against neuronal NOS, we observed that $n$ NOS-immunoreactivity was located in all four types of endocrine cells. Moreover, confocal microscopy disclosed coinciding profiles between cells expressing $n$ NOS-immunoreactivity and immunoreactivity for insulin, glucagon, pancreatic polypeptide and somatostatin, respectively. Taken together with the results from previous studies $[4-8,16]$ this data strongly suggest that a constitutive $n$ NOS resides in all these four cell types and in nervous structures as well. Moreover, results of most functional studies on the influence of NOS-inhibitors and NO donors on insulin and glucagon secretion favour NO as an important modulator of the secretory processes of these hormones [4-6, 8-11, 13-15, 43]. Although some early studies $[8,10]$ and a recent one (using islets from newborn rats) [18] suggested that NO had a positive effect on glucose-stimulated and L-arginine stimulated insulin release, we [4-6, 9, 14, 15, 44-46] and others $[13,43,47]$ have repeatedly shown that NO is strongly inhibitory to insulin secretion induced by these secretagogues. The inhibitory effect of NO on insulin release induced by nutrients is probably due to the formation of S-nitrosothiols [48], which impair important regulatory thiol groups. Thiol groups have long been shown to be essential for stimulus-secretion coupling induced by glucose $[49,50]$. In contrast, $\mathrm{NO}$ is a positive modulator of glucagon secretion, probably acting by stimulating the cyclic GMP system [5, 6, 44-46].

It has previously been shown that cytotoxicity mediated by cytokine can induce expression of HO-1 in cultured islets [23-25]. That we did not observe any immunocytochemical evidence for HO-1 expression in rats islets after injection with endotoxin does not exclude that HO-1 could be detected by other more sensitive methods but not by immunocytochemistry which might be too insensitive in the present situation. We have very recently obtained evidence for the presence of mechanisms mediated by HO-2 and $\mathrm{CO}$ in the release of insulin and glucagon from rat islets [26]. Thus, islet tissue was found to produce large amounts of $\mathrm{CO}$ [26]. As this $\mathrm{CO}$ production was strongly suppressed by the HO-inhibitor zinc protoporphyrin-IX (ZnPP-IX), and since both insulin and glucagon secretion from intact islets could be suppressed by ZnPP-IX and stimulated by the HO-substrate haemin, we concluded that $\mathrm{CO}$ should be recognized as a putative physiologic stimulator of insulin and glucagon release [26]. The data in this study strongly suggest that HO-2 resides in all four types of endocrine cells in rat pancreatic islets and confocal microscopy showed coinciding profiles between cells expressing HO-2 immunoreactivity and immunoreactivities for insulin and glucagon as well as for PP and somatostatin. Hence, the CO-pathway could be of functional significance as an intracellular modulator system, not only for the release of insulin and glucagon [26] but also for the secretion of PP and somatostatin. Thus, from the most recent data and those from this study it seems likely that $\mathrm{NO}$ as well as $\mathrm{CO}$ formed within the islets of Langerhans are capable of acting both within their cells of origin and also as paracrine, neurocrine or even as endocrine mediators.

In conclusion, we have shown the existence of a morphological substrate for a putative functional role of $i$ NOS, $n$ NOS and HO- 2 as important regulatory enzymes in the physiology and pathophysiology of hormone secretion from the islets of Langerhans.

Acknowledgements. The technical help of L. Thuresson and the secretarial help of E. Björkbom is gratefully acknowledged. This study was supported by the Swedish Medical Research Council (12X-11205, 14X-4286), the foundations of Crafoord, Magnus Bergvall, Albert Påhlsson, Thelma Zoëga and Åke Wiberg, the Swedish Diabetes Association and the Medical Faculty, University of Lund, Lund, Sweden. The generous supply of $i$ NOS and $n$ NOS-21 antisera by V. RiverosMoreno, Wellcome Research Laboratories, Beckenham, England is gratefully appreciated. 


\section{References}

1. Knowles RG, Moncada S (1994) Nitric oxide synthases in mammals. Biochem J 298: 249-258

2. Eizirik DL, Flodström M, Karlsen AE, Welsh N (1996) The harmony of the spheres: inducible nitric oxide synthase and related genes in pancreatic beta cells. Diabetologia 39: 875-890

3. Mandrup-Poulsen T (1996) The role of interleukin-1 in the pathogenesis of IDDM. Diabetologia 39: 1005-1029

4. Panagiotidis G, Alm P, Lundquist I (1992) Inhibition of islet nitric oxide synthase increases arginine-induced insulin release. Eur J Pharmacol 229: 277-278

5. Panagiotidis G, Åkesson B, Alm P, Lundquist I (1994) The nitric oxide system in the endocrine pancreas induces differential effects on the secretion of insulin and glucagon. Endocr 2: 787-792

6. Salehi A, Carlberg M, Henningson R, Lundquist I (1996) Islet constitutive nitric oxide synthase: biochemical determination and regulatory function. Am J Physiol 270 (Cell Physiol 39): C1634-C1641

7. Corbett JA, McDaniel ML (1995) Intra islet release of interleukin 1 inhibits $\beta$ cell function by inducing $\mathrm{B}$ cell expression of inducible nitric oxide synthase. J Exp Med 181: 559-568

8. Schmidt HHHW, Warner TD, Ishii K, Scheng H, Murad F (1992) Insulin secretion from pancreatic B cells caused by L-arginine-derived nitrogen oxides. Science 255: 721-723

9. Panagiotidis G. Åkesson B, Rydell EL, Lundquist I (1995) Influence of nitric oxide synthase inhibition, nitric oxide and hydroperoxide on insulin release induced by various secretagogues. Br J Pharmacol 114: 289-296

10. Laychock RG, Modica ME, Cavanaugh CT (1991) L-Arginine stimulates cyclic guanosine $3{ }^{\prime}, 5^{\prime}$-monophosphate formation in rat islets of Langerhans and RINm5F insulinoma cells: evidence for L-arginine: nitric oxide synthase. Endocrinology 129: 3043-3052

11. Jansson L, Sandler S (1991) The nitric oxide synthase inhibitor $\mathrm{N}^{\mathrm{G}}$-nitro L-arginine stimulates pancreatic islet insulin release in vitro, but not in the perfused pancreas. Endocrinology 128: 3081-3085

12. Jones PM, Persaud SJ, Bjaaland T, Pearson JD, Howell SL (1992) Nitric oxide is not involved in the initiation of insulin secretion from rat islets of Langerhans. Diabetologia 35: $1020-1027$

13. Gross R, Roye M, Manteghetti M, Hillaire-Buys D, Ribes $\mathrm{G}$ (1995) Alterations of insulin response to different $\beta$ cell secretagogues and pancreatic vascular resistance induced by $\mathrm{N}^{\omega}$-nitro-L-arginine methyl ester. Br J Pharmacol 116: 1965-1972

14. Åkesson B, Lundquist I (1996) Modulation of the islet nitric oxide system and sulphonylurea-induced insulin secretion. Diabetes Res 31: 91-99

15. Åkesson B, Mosén H, Panagiotidis G, Lundquist I (1996) Interaction of the islet nitric oxide system with L-arginineinduced secretion of insulin and glucagon in mice. $\mathrm{Br} \mathrm{J}$ Pharmacol 119: 758-764

16. Bouwens L, Klöppel G (1994) Cytochemical localization of NADPH-diaphorase in the four types of pancreatic islet cell. Histochemistry 101: 209-214

17. Burrell MA, Montuenga LM, Carcía M, Villaro AC (1996) Detection of nitric oxide synthase (NOS) in somatostatinproducing cells of human and murine stomach and pancreas. J Histochem Cytochem 44: 339-346

18. Spinas GA, Laffranchi R, Francoys I, David I, Richter C, Reinecke M (1998) The early phase of glucose-stimulated insulin secretion requires nitric oxide. Diabetologia 41: 292-299
19. Marks GS, Brien JF, Nakatsu K, McLaughlin BE (1991) Does carbon monoxide have a physiological function? Trends Pharmacol Sci 11: 185-188

20. Verma A, Hirsch DJ, Glatt CE, Ronnett GV, Snyder SH (1993) Carbon monoxide: a putative neural messenger. Science 259: 381-384

21. Maines MD (1988) Heme oxygenase: function, multiplicity, regulatory mechanisms, and clinical applications. FASEB J 2: $2557: 2568$

22. Vreman HJ, Stevenson DK (1988) Heme oxygenase activity measured by carbon monoxide production. Anal Biochem 168: 31-38

23. Helqvist S, Polla BS, Johannesen J, Nerup J (1991) Heat shock protein induction in rat pancreatic islets by recombinant human interleukin $1 \beta$. Diabetologia 34: 150-156

24. Strandell E, Buschard K, Saldeen J, Welsh N (1995) Interleukin $1 \beta$ induces expression of HSP70, heme oxygenase and Mn-SOD in FACS-purified rat islet $\beta$-cells, but not in $\alpha$-cells. Immunol Lett 48: $145-148$

25. Welsh N, Sandler S (1994) Protective action by hemin against interleukin $1 \beta$ induced inhibition of rat pancreatic islet function. Mol Cell Endocrinol 103: 109-114

26. Henningsson R, Alm P, Lundquist I (1997) Occurrence and putative hormone regulatory function of a constitutive heme oxygenase in rat pancreatic islets. Am J Physiol 273: C703-C709

27. Bruss ML, Black AL (1978) Enzymatic microdetermintion of glycogen. Anal Biochem 84: 309-312

28. Lyons CR, Orloff GJ (1992) Molecular cloning and functional expression of an inducible nitric oxide synthase from a murine macrophage cell line. J Biol Chem 267: 6370-6374

29. Hamid Q, Springall DR, Riveros-Moreno V et al. (1993) Induction of nitric oxide synthase in asthma. Lancet 342: 1510-1513

30. Alm P, Larsson B, Ekblad E, Sundler F, Andersson K-E (1993) Immunohistochemical localization of peripheral nitric oxide synthase-containing nerves using antibodies raised against synthesized $\mathrm{C}$ - and $\mathrm{N}$-terminal fragments of a cloned enzyme from rat brain. Acta Physiol Scand 148: 421-429

31. Springall DR, Riveros-Moreno V, Buttery L et al. (1992) Immunological detection of nitric oxide synthase(s) in human tissues using heterologous antibodies suggesting different isoforms. Histochemistry 98: 259-266

32. Bredt DS, Hwang PM, Glatt CE, Lowenstein C, Reed RR, Snyder SH (1991) Cloned and expressed nitric oxide synthase structurally resembles cytochrome P-450 reductase. Nature 351: 714-718

33. Johnson GD, Araujo GM (1981) A simple method of reducing the fading of immunofluorescence during microscopy. J Immunol Methods 43: 349-350

34. Wessendorf MW, Elde RP (1985) Characterization of an immunofluorescence technique for the demonstration of coexisting neurotransmitters within nerve fibers and terminals. J Histochem Cytochem 33: 984-994

35. Ny L, Alm P, Larsson B, Ekström P, Andersson KE (1995) The nitric oxide pathway in cat esophagus: localization of nitric oxide synthase and functional aspects. Am J Physiol 268: G57-G70

36. Ekholm R, Ericson LE, Lundquist I (1971) Monoamines in the pancreatic islets of the mouse. Subcellular localization of 5-hydroxytryptamine by electron microscopic autoradiography. Diabetologia 7: 339-348

37. Lundquist I, Ahrén B, Håkanson R, Sundler F (1979) The role of intracellular amines in the regulation of islet cell function. In: Waldhäusl WK (ed) Proc 10th Congr Intern 
Diabetes Fed, Sept 9-14, Vienna, Austria, Exerpta Medica, Amsterdam-Oxford-Princeton, pp 57-63

38. Umehara K, Kataoka K, Ogura T et al. (1997) Comparative distribution of nitric oxide synthase (NOS) in pancreas of the dog and rat: immunocytochemistry of neuronal type NOS and histochemistry of NADPH-diaphorase. Brain Res Bull 42: 469-474

39. Wessendorf MW, Brelje TC (1992) Which fluorophore is brightest? A comparison of the staining obtained using fluorescein, tetramethylrhodamine, lissamine rhodamine, Texas Red and cyanine 3.18. Histochemistry 98: 81-85

40. Vincent SR (1992) Nitric oxide and arginine-evoked insulin secretion. Science 258: 1376

41. Shimosegawa T, Abe T, Satoh A et al. (1993) NADPH-diaphorase activity in neurons of the mammalian pancreas: coexpression with vasoactive intestinal polypeptide. Gastroenterology 105: 999-1008

42. Wörl J, Wiesand M, Mayer B, Greskötter K-R, Neuhuber WL (1994) Neuronal and endothelial nitric oxide synthase immunoreactivity and NADPH-diaphorase staining in rat and human pancreas: influence of fixation. Histochemistry 102: $353-364$

43. Cunningham JM, Mabely JG, Delaney CA, Green IC (1994) The effect of nitric oxide donors on insulin secretion, cyclic GMP and cyclic AMP in rat islets of Langer- hans and the insulin-secreting cell lines HIT-T15 and RINm5F. Mol Cell Endocrinol 102: 23-29

44. Salehi A, Parandeh F, Lundquist I (1998) Signal transduction in islet hormone relase: interaction of nitric oxide with basal and nutrient-induced hormone responses. Cellular Signalling 10: 645-651

45. Henningsson R, Lundquist I (1998) Arginine-induced release of insulin is decreased and glucagon increased in parallel with islet NO-production. Am $\mathrm{J}$ Physiol 275: E500-E506

46. Åkesson B, Lundquist I (1998) Evidence for nitric oxide mediated effects on islet hormone secretory phospholipase C signal transduction mechanisms. Biosci Rep 18: 199-213

47. Sjöholm $\AA$ (1996) Nitric oxide donor SIN-1 inhibits insulin release. Am J Physiol 271: C1098-C1102

48. Stamler JS, Simon DI, Osborne JA et al. (1992) S-nitrosylation of proteins with nitric oxide: Synthesis and characterization of biologically active compounds. Proc Natl Acad Sci USA 89: 444-448

49. Hellman B, Idahl L- ̊, Lernmark Å, Sehlin J, Täljedal I-B (1974) Membrane sulphydryl groups and pancreatic beta cell recognition of insulin secretagogues. Exerpt Med Int Congr Ser 312: 65-78

50. Ammon HPT, Mark M (1985) Thiols and pancreatic $\beta$-cell function: a review. Cell Biochem Funct 3: 157-171 